\title{
Internal iliac artery ligation to combat post partum haemorrhage: an institutional review of case series
}

\author{
Anushree Jain*, Rekha Uttam Sapkal
}

Department of Obstetrics and Gynecology, People's College of Medical Sciences and Research Centre, Bhopal, Madhya Pradesh, India

Received: 27 February 2017

Revised: 23 April 2017

Accepted: 24 April 2017

\section{*Correspondence:}

Dr. Anushree Jain,

E-mail: anushree.jain10@gmail.com

Copyright: ( ) the author(s), publisher and licensee Medip Academy. This is an open-access article distributed under the terms of the Creative Commons Attribution Non-Commercial License, which permits unrestricted non-commercial use, distribution, and reproduction in any medium, provided the original work is properly cited.

\section{ABSTRACT}

Background: Internal iliac artery supplies the pelvic viscera. IIAL is a valuable surgical procedure to control intractable pelvic haemorrhage with the mainstay aim of uterus preservation. There is a reduction of $85 \%$ in pulse pressure and $48 \%$ in the blood flow in the arteries distal after internal iliac artery ligation. Thus, the expertise to perform IIAL should be present in armamentarium of every obstetrician and gynaecologist.

Methods: Retrospective review of 22 cases who have undergone IIAL or Peripartum hysterectomy for management of Post- Partum haemorrhage in the study period of January 2012 till December 2015 in the Department of Obstetrics and Gynaecology of People's College of Medical Science and Research Centre, Bhopal.

Results: Internal iliac artery ligation was performed in 53\% out of which $31.8 \% \%$ was for placenta previa, $4.54 \%$ for adherent placenta, 9.1\% IIAL for Atonic PPH. Whereas peripartum hysterectomy was performed in $38 \%$ cases out of which $13.6 \%$ had perforation of uterus. $9 \%$ underwent hysterectomy as well as IIAL. Blood loss more than two 2 liters within period of $60-90$ mins was effectively and dramatically controlled with IIAL. Thus, maternal mortality reduced while preserving fertility. Control of Pelvic hemorrhage was achieved in $100 \%$ of cases.

Conclusions: Bilateral ligation of the internal iliac arteries is a safe, rapid and very effective method of controlling bleeding from UTERUS and genital tract. It plays a major role in safe guarding the patient from undergoing life threatening consequences due to pelvic haemorrhage.

Keywords: Internal iliac artery ligation, Peripartum hysterectomy, Postpartum haemorrhage, Uterus preservation

\section{INTRODUCTION}

Postpartum haemorrhage (PPH) is a major cause of worldwide maternal mortality ranging from $13 \%$ in developed countries to $34 \%$ in developing countries. ${ }^{1}$ It is reportedly responsible for over 125000 maternal deaths each year and is associated with morbidity in 20 million women per year. ${ }^{2}$ Post-partum haemorrhage is definitely a nightmare for all obstetricians. Uterine atony is the commonest cause of PPH that accounts for $80 \%$ of cases. ${ }^{3}$ Known risk factors for occurrence of PPH include a history of PPH, history of retained placenta, placental abruption, placenta previa, PIH, GDM, uterine fibroids, hydramnios, and multiple pregnancies, augmentation of labour, prolonged labour and difficult or failed instrumental delivery, cervical and vaginal lacerations. There is danger of extension of c section incision either in broad ligament or to cervix. Where the site of operation is difficult to reach for prompt haemostasis.

Major PPH or loss of over $1000 \mathrm{ml}$ of blood occurs in 1$5 \%$ of deliveries. When PPH continues despite aggressive 
medical treatment, early consideration should be given to surgical intervention. The choice of procedure will depend on the parity of the women and her desire for childbearing, the extent of hemorrhage and, most importantly, the experience and judgement of the surgeon.

In most catastrophic situations, hysterectomy is preferred as a first choice in order to arrest further blood loss. Although a life-saving procedure, it may not be appropriate for women who need to preserve their reproductive potential.

Hemostatic procedures that preserve the uterus include uterine cavity tamponade, selective uterine artery embolization, uterine artery ligation and uterine brace sutures. Internal iliac artery ligation (IIAL) has been advocated as an effective means of controlling intractable PPH and preventing maternal death. Following ligation of anterior branch of internal iliac artery, there is a reduction of $85 \%$ in pulse pressure and $48 \%$ in the blood flow in the arteries distal to the ligation. ${ }^{4,5}$ It is also helpful in controlling massive broad ligament hematoma. Here we have reviewed the case series of patients who underwent IIAL and or peripartum hysterectomy for the control of post-partum haemorrhage. Hence the main aim of this study is to identify and analyse the clinical conditions where there is need for any of surgical method to control the blood loss. Thus, effectiveness of Internal iliac artery ligation was analysed.

\section{METHODS}

Retrospective review of case series conducted in the Department of Obstetrics and Gynaecology of People's College of Medical Science and Research Centre, Bhopal during the study period from January 2012 to December 2015. It included all the 22 women who have undergone IIAL or Peripartum hysterectomy for management of Post-Partum haemorrhage. The cases were studied under various variables such as parity and gestational age, mode of delivery was documented.

Amount of blood loss (millilitres) and duration to control PPH by IIAL or peripartum hysterectomy was analysed. Additional variables studied were complications like shock, septicaemia, Disseminated Intravascular Coagulopathy, deep vein thrombosis, renal failure, liver failure, electrolyte imbalance and Post-operative duration of hospital stay.

\section{RESULTS}

Out of 22 case studies maximum cases belonged to $4^{\text {th }}$ para accounting to $41 \%$ who underwent IIAL for the management of PPH followed by $2^{\text {nd }}$ para contributing to $22.70 \%$. Other cases belonged to primipara, $3^{\text {rd }}, 5^{\text {th }}$ and $6^{\text {th }}$ para contributing to $9.10 \%$ respectively (Table 1 ).
Table 1: Parity distribution observed in this study.

\begin{tabular}{|lll|}
\hline Parity & No. of cases & $\%$ \\
\hline Primigravida & 2 & 9.10 \\
\hline $2^{\text {nd }}$ gravida & 5 & 22.70 \\
\hline $3^{\text {rd }}$ gravida & 2 & 9.10 \\
\hline $4^{\text {th }}$ gravida & 9 & 41 \\
\hline $5^{\text {th }}$ gravida & 2 & 9.10 \\
\hline $6^{\text {th }}$ gravida & 2 & 9.10 \\
\hline
\end{tabular}

In this study $86 \%$ affected patients were from the preterm group. Whereas the pre-viable group also contributed $14 \%$ (Figure 1).

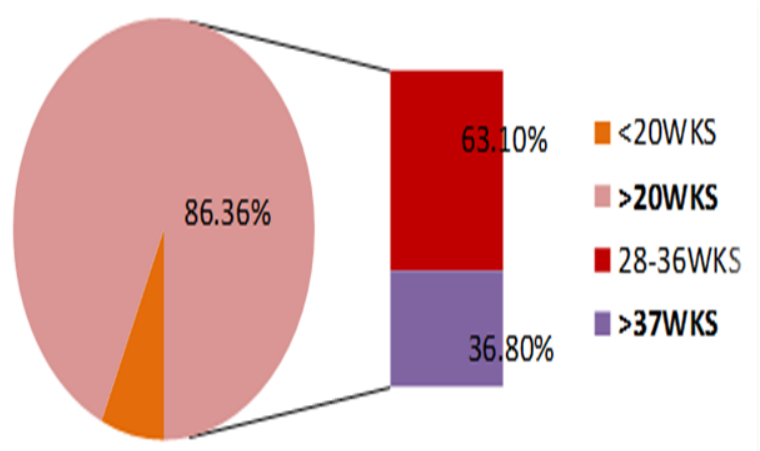

$13.63 \%$

Figure 1: PPH observed at pre-viability and viabile gestation.

Table 2: Mode of delivery.

\begin{tabular}{|llll|}
\hline $\begin{array}{l}\text { Mode of } \\
\text { delivery }\end{array}$ & $\begin{array}{l}\text { No. of } \\
\text { cases }\end{array}$ & Lial & Hysterectomy \\
\hline LSCS & 12 & $10(45.5 \%)$ & $2(9 \%)$ \\
\hline Emergency & 10 & $2(9 \%)$ & 0 \\
\hline Elective & 2 & & \\
\hline $\begin{array}{l}\text { Vaginal } \\
\text { delivery }\end{array}$ & 5 & & $4(18 \%)$ \\
\hline FTND & 4 & 0 & $1(4.5 \%)$ \\
\hline PTVD & 1 & 0 & 0 \\
\hline Abortion & 2 & $2(9 \%)$ & $1(4.5 \%)$ \\
\hline Laprotomy & 3 & $2(9 \%)$ & \\
\hline
\end{tabular}

Amongst all the 22 cases the indications of IIAL are placental causes like placenta previa accounting to $31.8 \%$, placenta accreta $4.54 \%$.Post-partum haemorrhage caused after delivering of intrauterine dead foetus (IUFD) and malpresenting foetuses also required IIAL in $9.1 \%$ cases.

Other causes with significant contributions were ectopic pregnancy, abortions and PPH occurring in previous caesarean sections accounting to $4.54 \%$ respectively (Table 2). 
In contrast, indications for Peripartum hysterectomy were ruptured uterus (13.63\%), post-partum haemorrhage $(9.1 \%)$, placenta percreta, accreta and IUFD resulting in $4.54 \%$ respectively (Table 2 ).

Out of 22 cases there were 5 vaginal deliveries and 2 emergency LSCS cases required obstetric hysterectomy to control postpartum hemorrhage. Whereas in 2 elective LSCS bleeding was controlled with ILAL only. Effective control was observed in 45- 90 minutes (Table 3).

Table 3: Blood loss and need of IIAL/ hysterectomy.

\begin{tabular}{|lll|}
\hline Blood Loss & Hysterectomy & IIAL \\
\hline$>1500 \mathrm{ml}$ & $5(23 \%)$ & $13(59 \%)$ \\
\hline $1000 \mathrm{ml}-$ & $4(18 \%)$ & $2(9 \%)$ \\
$1500 \mathrm{ml}$ & & \\
\hline
\end{tabular}

In the given scenario, the amount of blood loss more than $1500 \mathrm{ml}$, in $59 \%$ cases the decision of IIAL was effective. Whereas where the blood loss less than $1500 \mathrm{ml}$, hysterectomy was tried initially in $9 \%$ cases but was followed by IIAL (Table 4).

Table 4: Time lapsed in performing the procedure.

\begin{tabular}{|lll|}
\hline Time Lapsed & Hysterectomy & IIAL \\
\hline$>90$ mins & $5(23 \%)$ & $8(53 \%)$ \\
\hline $45-90$ mins & $4(18 \%)$ & $6(40 \%)$ \\
\hline$<45$ mins & 0 & $1(7 \%)$ \\
\hline
\end{tabular}

In $7 \%$ cases the bleeding was profuse over $45 \mathrm{mins}$ where IIAL was effective. In $40 \%$ cases blood loss was over 90 mins where hemostasis could not be achieved. Hence, $23 \%$ cases underwent hysterectomy where as $53 \%$ cases had IIAL (Table 5).

Table 5: Management to control PPH.

\begin{tabular}{|ll|}
\hline Procedure & No. of cases \\
\hline Bilateral internal iliac artery ligation & $14(64 \%)$ \\
\hline Unilateral internal iliac artery ligation & $1(5 \%)$ \\
\hline Subtotal hysterectomy & $9(41 \%)$ \\
\hline IIAL and Subtotal hysterectomy & $2(9 \%)$ \\
\hline
\end{tabular}

All the registered cases were initially managed medically but it failed to control the intractable haemorrhage and $100 \%$ success was achieved by IIAL or peripartum hysterectomy (Table 6).

\section{DISCUSSION}

As per the observations it was found that increasing parity was more prone to land up with PPH i.e. In our study amongst 22 cases were reviewed and Internal iliac artery ligation was performed in $53 \%$ cases and had $100 \%$ efficient result whereas hysterectomy was performed in $38 \%$ cases. $9 \%$ underwent hysterectomy as well as IIAL.
Table 6: Indications for IIAL or post-partum hysterectomy.

\begin{tabular}{|llll|}
\hline Indications & No. & IIAL & Hysterectomy \\
\hline Malposition & 2 & $2(9.1 \%)$ & - \\
\hline Previous LSCS & 1 & $1(4.54 \%)$ & - \\
\hline $\begin{array}{l}\text { Ectopic } \\
\text { pregnancy }\end{array}$ & 1 & $1(4.54 \%)$ & - \\
\hline PPH & 2 & - & $2(9.1 \%)$ \\
\hline Ruptured uterus & 3 & - & $3(13.63 \%)$ \\
\hline Abortion & 1 & $1(4.54 \%)$ & - \\
\hline Placenta & & & \\
\hline Previa & 7 & $7(31.8 \%)$ & - \\
\hline Accreta & 1 & $1(4.54 \%)$ & $1(4.54 \%)$ \\
\hline Percreta & 1 & - & $1(4.54 \%)$ \\
\hline IUF & 3 & $2(9.1 \%)$ & $1(4.54 \%)$ \\
\hline
\end{tabular}

Joshi VM conducted a study titled internal iliac artery ligation for arresting postpartum haemorrhage, March 2007.6 In this study out of 60 selected patients 15 underwent unilateral ligation and 45 underwent bilateral ligation. Haemorrhage was effectively controlled in 53 cases. Evsen MS et al conducted a study titled Internal iliac artery ligation for severe postpartum haemorrhage. ${ }^{7}$ In this study out of 110 patients registered hysterectomy was performed in $39.3 \%$ cases and thus, early resort to IIAL effectively prevents hysterectomy.

In this study, it was observed that blood loss more than or equal to 2 liters within period of 60-90 minutes had IIAL effective in preventing the women fertility as well as mortality.

Whereas $36.34 \%$ IIAL was done for placenta previa and adherent placenta. 18.2\% IIAL for Atonic PPH. 3 cases were little outstanding for pelvic haemorrhage with uterine rupture because of cornual pregnancy and other because of post Dilatation and Curettage uterine perforation and one with uterine inversion. Refae W conducted a study on prophylactic bilateral internal artery ligation for management of low-lying placenta accreta: a prospective study. Bilateral internal iliac artery ligation was performed in patients with invasive placenta (accreta and increta) $(46 / 51=90.1 \%)$ and satisfactory haemostasis was achieved in 38 patients $(38 / 46=82.6 \%) .{ }^{8}$ In five patients with placenta previa increta $(5 / 17=29.4 \%)$, there was uncontrolled blood loss; thus, we proceeded to caesarean hysterectomy.

The mean intraoperative blood loss was $1255 \pm 589 \mathrm{ml}$. Blood transfusion was necessary in 35 patients $(35 / 46=76 \%)$ during the operations.

In this study mortality was observed in 1 case (5\%) associated with couvelier uterus and post obstetric hysterectomy because of Disseminated Intravascular Coagulopathy and multiorgan dysfunction syndrome after 30 days of surgery. Control of Pelvic haemorrhage was achieved in $100 \%$ of cases. 


\section{CONCLUSION}

This is one of the most effective procedures to save women's life from intractable pelvic hemorrhage. Further prevents them from undergoing hysterectomy and its related consequences. IIAL is effective in combating pelvic haemorrhage in a short span of time is lifesaving in $100 \%$ cases. Hence, the duration as well as the amount of blood loss governs the prompt decision in favor of IIAL. It is truly recommended to befriend with IIAL because of its high efficiency and better prognosis.

\section{ACKNOWLEDGMENTS}

Authors would like to thanks Dr. Rekha Uttam Sapkal, Professor and HOD, Obstetrics and Gynaecology, PCMS, Bhopal for enlightening and making us learn the importance of IIAL and developing confidence for performing this procedure.

Funding: No funding sources Conflict of interest: None declared

Ethical approval: The study was approved by the Institutional Ethics Committee

\section{REFERENCES}

1. Khan KS, Wojdyla D, Say L, Gulmezoglu AM, Van Look PF. WHO analysis of causes of maternal death: a systematic review. Lancet. 2006;367:1066-74.
2. Selo-Ojeme DO. Primary post-partum haemorrhage. J Obstet Gynecol. 2002;22:463-9.

3. Arulkumaran S, De Cruze B. Surgical management of severe postpartum haemorrhage. Curr Obstet Gynecol. 1999;8:101-5.

4. Siegel P, Mengert WF, Internal Iliac Artery Ligation in Obstetrics and Gynecology. JAMA. 1961;178(11):1059-62.

5. Burchell RC. Physiology of internal iliac artery ligation. BJOG: An International J Obstetr Gynaecol. 1968;75(6):642-51.

6. Joshi VM, Otiv SR, Majumder R, Nikam YA, Shrivastava M. Internal iliac artery ligation for arresting postpartum haemorrhage; BJOG. 2007;114(3):356-61.

7. Siddık EM, Erdal SM, Ender SH, Serdar B, Cetin B, Sibel S, Talip G. Internal iliac artery ligation for severe postpartum hemorrhage. Ginekol Pol. 2012;83:665-8.

8. Refaie W, Fawzy M, Shabana A. Prophylactic bilateral internal iliac artery ligation for management of low-lying placenta accreta: a prospective study. Tanta Med J. 2014;42:146-50.

Cite this article as: Jain A, Sapkal RU. Internal iliac artery ligation to combat post partum haemorrhage: an institutional review of case series. Int J Reprod Contracept Obstet Gynecol 2017;6:2347-50. 